\title{
Application of Metacognitive Strategy to Primary Listening Comprehension of Japanese
}

\author{
Yansong Qu \\ Japanese Language Department \\ Dalian Neusoft University of Information \\ Liaoning, China 116023
}

\begin{abstract}
Listening is an important language skill for foreign language study, and is the basic of effective communication. But it is hard to improve Japanese listening comprehension ability for Chinese student. For the past few years, meta-cognitive awareness and listening strategies have been widely recognized in the process of listening comprehension. This article is based on the theory of metacognitive research, discussed how to teach student's metacognitive in the primary listening teaching of Japanese, improve students' listening comprehension abilities.
\end{abstract}

Keywords-listening comprehension; Japanese primary listening comprehension; metacognitive strategy

\section{INTRODUCTION}

Foreign language listening is influenced by many factors, such as mother tongue listening ability, foreign language ability, voice memory skill, vocabulary knowledge, metacognitive knowledge and so on. From 1990s to now, with the development of cognitive psychology, scholars both domestic and abroad have begun to actively explore the processing of awareness and strategy, gradually discover the importance of metacognition for listening, and have achieved fruitful research results. Compared with the results of metacognitive research in English listening, there are less researches on Japanese Metacognition listening. On the basis of demonstrating the necessity and feasibility of integrating metacognitive strategy for the primary Japanese listener, this article discusses the combination of planning, monitoring and evaluation strategies with the learning tasks before, during and after listening activities, and integrating the training of metacognitive strategies into the teaching of listening class. Apply metacognitive awareness to listening.

\section{THEORETICAL BACKGROUND}

The concept of metacognition was first proposed by an American psychologist named Flavell (1979) and Flavell believes that metacognition is about the cognitive process and result of the subject itself, or all related knowledge. It can be basically divided into three aspects: metacognitive knowledge, metacognitive experience and metacognitive monitoring. In practical research, people often combine metacognitive experience with metacognitive monitoring together. So the research of metacognition usually consists of two parts: metacognitive monitoring and regulation (Dongqi,
1989). Considering metacognitive theory, based on learning cognitive psychological processes O'Malley \& Chamot (1990) divides learning strategies into three categories: cognitive strategy, metacognitive strategy and social/emotional strategy. Cognitive strategy is the most widely used strategy for two language learners. The cognitive strategy consists of four elements: (1) practice; (2) receiving and sending information; (3) analyzing and reasoning; (4) the structure of input and output. Among them, practice is the most important cognitive strategy. The metacognitive strategy is a cognitive strategy that transcends cognitive functions or is accompanied by cognitive functions It means the learner's self-regulation and cognitive function, which is used in the whole learning process. It is an indispensable strategy in the process of language study. Social emotional strategy is also an important strategy in the process language study. Oxford (1990) divided social affective strategies into three categories: (1) asking questions; (2) collaborate with others; (3) transferring emotions to others. The most basic social affective strategy is to ask questions. Through questioning, learners can get close to their own understanding and questions and get direct and indirect feedback from each other.

\section{THE Role of METACOGNITIVE StRATEgIES IN JAPANESE ELEMENTARY LISTENING COMPREHENSION}

The teaching goal of listening comprehension at the primary stage of Japanese is taken as an example of the goal published by the center for education and research of Waseda University in 2008. It mainly helps students to recognize the pronunciation of Japanese, hear the pronunciation and intonation of words and sentences correctly, the changing pronunciation of sentences and daily conversations. JLPT official website suggests that listening candidates should master Japanese language features such as pronunciation, intonation, repetition and ellipsis. It will hinder the progress of listening comprehension if we do not understand the language characteristics of Japanese. In addition, Japanese junior learners may face the difficulties of lack of vocabulary, understanding of Japanese society, cultural knowledge and so on, these difficulties may cause nervousness and anxiety during listening, reduce the validity of information processing, and increase the difficulty of listening. It is not only primary Japanese learners, but also students learned Japanese for many years, they may have 
high ability in grammar, words and reading, but they often not good at conversation. According to the Japanese International Education Support Association, for the first Japanese proficiency test in 2008 and 2009 the average scores of vocabulary, grammar and reading were above $60 \%$, only the average score of listening comprehension was the lowest and the correct rates were lower than $60 \%$. This situation is related to the lack of training in listening strategy.

Because of the fleeting characteristic of Japanese listening, the process of listening is inseparable from the activities of memory and speculation. In addition, speaking, reading and writing can control the different rhythm according to their own actual situation, listening need listener to be highly dependent on the speaker's voice speed, the content of speech and so on, cannot be completely controlled by the listener himself. Therefore, listening is closely related to the listener's subjective consciousness, cultural background and metacognition. Goh (2008) pointed out that the application of metacognitive concept to listening study can help to better analyze the efforts of the learners in the process of listening comprehension, to examine the development of the listening level, to evaluate the realization of the listening goal and to regulate the listening task in a timely manner. Listening comprehension is a psychological process of the listener's active decoding and construction of speech and nonverbal information. Listening strategy play a very important role in the process of listening comprehension. Especially, metacognitive strategy training can improve the flexibility, appropriateness and coordination of the students' strategy selection and use (Zhang Zhenghou, 2013). The ultimate goal of strategy training is to arouse students' metacognitive awareness and to control their own learning. Metacognitive awareness is the premise of improving autonomous learning ability. Therefore, metacognitive strategy training for students in the primary listening stage will have a profound positive impact on students' future learning.

\section{The APPlication OF METACOGNITIVE STRATEGIES IN JAPANESE PRIMARY — LISTENING TEACHING}

Oxford (1990) pointed out that the learning style and learning experience are difficult to change, but learning strategy can be trained and corrected. Chamot\&Küpper (1989) believed that strategy training in normal teaching is better than centralized instruction. Therefore, it is necessary to carry out metacognitive strategy training and foreign language teaching activities simultaneously. Combine the content explanation or demonstration strategy in the classroom, teachers help the students to practice and learn to use the strategy during the process of completing the task. $\mathrm{O}$ 'Malley \& Chamot (1990) are also the first two researchers to link the metacognitive and listening teaching. They have studied the effectiveness of metacognitive strategy and concluded that metacognitive strategies play an important role in improving listening level. According to the research results of Underwood (1989), listening activity can be divided into 3 stages: before, during and after listening. Therefore, in the course of listening teaching, we use this model to guide students to carry out their mental activities to obtain correct listening comprehension, and to promote the acquisition of metacognitive strategies in planning, monitoring and evaluation.

\section{A. Pre-listening Strategy}

$\mathrm{Xu}$ Xiangdong (1993) pointed out that the level of listening comprehension mainly depends on whether there is enough information in the mind. Therefore, in the pre listening teaching activities, teachers should activate the students' knowledge background through preview. At the same time guide students to think about the background knowledge, cultural information, and predict the content of the listening materials, so that the students can understand the tasks to be accomplished and they can be encouraged to relax themselves. As an example of desire and decision in the first lesson of the second book of the new classic Japanese listening course, the teacher can guide the students to think about the Japanese sentence patterns and expressions of desire and decision, and make use of the key words of their interests and aspirations, and summarize the key points of use. And the difficulties. At the same time, students can be encouraged to discuss the employment and career outlook of Japanese. In this way, students will have a certain psychological preparation for the materials they will listen to, understand the topic, easy to guess at the time of listening, and reduce the anxiety and anxiety caused by the fear that they may not understand. This is an important part of the metacognitive strategy training.

\section{B. During Listening Strategy}

During listening, if students have to deal with a large amount of information in a certain period of time, Some students will not be able to deal with the information quickly because of the speed, vocabulary, grammar, background knowledge and so on. It may cause panic in the face of new input information. Teachers need to teach students some skills to relieve their anxiety, such as when they encounter information that not understand in the process of hearing, they can keep up the ideas of audio by taking notes and associating speculating. In addition, some students in low level of listening may translate the information one by one and consume a lot of time. When new information is entered, it cannot be processed in time, causing hearing impairment. Teachers should remind students in their classes to avoid using translation strategies. To grasp the key information is also an important strategy in listening comprehension, and to judge and deal with what information is important and what is not to the listener. You can't focus on all the contents you hear, if so you could not grasp the overall context. Teachers can organize group discussion and summarization to guide students to grasp the key points of listening comprehension.

\section{Post-listening Strategy}

After completing the task of listening, teachers can help students assess, reflect and examine the content of the learning process, the process of learning, the results of the study and the methods and strategies they have adopted through a questionnaire and a group discussion. Encourage students to evaluate their learning activities. Through the 
analysis and summary of the listening materials and the communication of some psychological conditions during listening, the students are encouraged to find their own strengths and weaknesses, and to improve their selfconfidence and focus on the next hearing.

\section{CONCLUSION}

The effectiveness of metacognitive listening teaching has been widely recognized domestic and abroad. However, metacognitive factors have not been paid enough attention in Japanese Listening Teaching at present. In the course of teaching, if the teachers can strengthen the training of students' original cognitive strategies and let the students master the necessary listening strategies, the students can also manage their listening learning tasks independently when they leave the teacher after class, so as to achieve better learning results.

\section{REFERENCES}

[1] Chamot, A. U.,\&Küpper, L. Learning strategies in foreign language instruction[J]. Foreign Language Annals. 1989. 22(1):13-24

[2] Flavell,J.H. Metacognition and cognitive monitoring:a new area of cognitive-developmental inquiry[J].American Psychologist. 1979.34(10):906-911.

[3] Goh C. Metacognitive instruction for second language listening development: Theory,practice and research im-plications[J]. RELC Journal. 2008. 39(2): $188-213$.

[4] O' Malley JM \&AV Chamot. Learning strategies in sec-ond language Acquisition[M] .Cambridg e:Cambridge University Press, 1990.

[5] Oxf ord, R. L. Language Learning Strategies : What Every Teacher Should Know [M] . New York : New bury House. 1990.

[6] Underwood.,M. Teaching Listening[M]. London:longman. 1989

[7] Vandegrift,L.,C. M. Goh,C. J. Mareschal \& M. H. Tafaghodtari. The metacognitive awareness listening questionnaire: development and validation[J]. Language Learning. 2006. 56( 3)

[8] Dongqi.Discussion on Metacognition. Journal of Beijing Normal University(Social Sciences). 1989 (1):68-74.

[9] Xu Xiangdong. Some experiences on the teaching of basic Japanese Listening. Journal of Japanese Language Study and Research. 1993(3)29-34

[10] Zhang Zhenghou. Feng Haiyun. FuYoulong. Wanghui. The mediating effect of listening strategies on metacognitive awareness and English listening achievement. Domestic foreign language. 2013(5):12-18 